\title{
sciendo
}

DOI: $10.2478 /$ jolace-2021-0009

\section{Metamorphoses of the conceptualization of SPORT in audio-visual translation}

\author{
Saule Petroniene, Saulute Juzeleniene, \& Artur Listov \\ Kaunas University of Technology, Lithuania \\ saule.petroniene@ktu.lt, saulute.juzeleniene@ktu.lt
}

\begin{abstract}
Due to the interrelation with culture, politics, economy and other major spheres of social life, SPORT discourse occupies quite a significant part of a modern society, therefore, the analysis of SPORT metaphors is important and necessary. The research of conceptual metaphor within the framework of translation studies is a relatively new and unexplored field in Lithuanian linguistics. Since SPORT metaphors are especially popular in political communication, the cases where sport in public discourse is considered as a visualization of policies and related areas are frequently investigated. The aim of the research was to reveal translation strategies used for the translation of SPORT metaphors from English to Lithuanian in audiovisual discourse related to SPORT. The research revealed that four translation strategies, namely: word for word translation, substitution, paraphrase, complete omission and retention were employed by the translators. The results of the research also demonstrated, that the most frequent source domain for the sport metaphors was WAR, which was the most frequently preserved using word for word translation strategy. In the case of other translation strategies, either the source domain was substituted in the translated text, or, in the majority of cases, the metaphorization was escaped. The target domain SPORT was represented similarly in both the source and the target languages, either implicitly by a larger context, or explicitly by lexical units containing a semantic element "related to SPORT". The research revealed that while choosing the translation strategy for the translation of conceptual metaphors, three key factors should be taken into consideration, such as cultural, cognitive and sociological factors.

Conceptual metaphors are an inseparable part of SPORT and they reveal in what terms SPORT can be defined in a particular culture. In order to understand how conceptual metaphors are perceived and what ideas are conveyed it is necessary to analyse the way they are transferred from the source culture to the target one.
\end{abstract}

Key words: : conceptual metaphor, translation, sport metaphor, cognitive linguistics, translation

\section{Introduction}

Sport, as a social phenomenon, is significant in modern world, it is intertwined with culture, politics, economics, etc. The discourse of sport is of interest to linguists whose work is related to the field of cognitive science and who try to understand and reveal mental structures involved in the construction and production of meaning.

The Conceptual metaphor theory (CMT) is based on perceiving one thing (target domain) in terms of another (source domain). Typically, target concepts are abstract and less familiar areas of experience, while source concepts relate to specific and well-known fields (Landowsky, 2012). According to Semino, "the choice of one metaphor rather than another has consequences for how a particular issue is 'framed' or structured, which aspects are foregrounded and which backgrounded, what inferences are facilitated, what evaluative and emotional associations are triggered, what courses of action appear to be possible and so on" (Semino, 2008, p. 91). The idea is important for this research as it may be assumed that SPORT, as a target domain, may be structured by more than one source domain, moreover, when the translation process is involved, the source domains may experience a shift due to cultural factors, translation strategies, etc., which may cause 
different conceptualisation of a target domain in target and source languages. In the paper it is demonstrated that this is indeed the case.

According to Kövecses (2002, p. 84), as source and target concepts are composed of several constituents, there may be several source domains which become activated during the process of mapping from the source to the target concepts. Thus, from its characterization, it is obvious that metaphor is not solely a linguistic phenomenon (Kövecses, 2005, p. 9), and it may occur in a language, brains, a body and social-cultural practice, though, metaphor in mind is the most important one. One of the peculiarities of the concept of SPORT as a target domain, is the prevalence of attributes related to the concept of WAR, as a source domain (Charteris-Black, 2004; Kövecses, 2005; Nordin, 2008; Bergh, 2011; Kudrin, 2011; Semino, 2008; Shekhovskaya, 2020). As Lewandowski (2011) indicates, conflict-related conceptual metaphors are very frequently used in soccer discourse.

Furthermore, metaphor translation one of the highlighted problems in translation studies; as Fernandez (2012) states, translatability of metaphor and its translation procedures are the main issues in translation studies related to metaphor (Fernandez 2012). Problems in translation may be caused by metaphors based on a culture, because in some cases some equivalent concepts may not exist in a source culture (Pedersen 2015). Moreover, metaphor may result in mistranslation, or the loss of metaphor may be experienced due to the translator's misinterpretation of the original text, therefore, a different meaning or a different concept may be brought into the translated text (Fernandez 2012).

As this paper deals with an audio-visual type of translation, subtitles in particular, it should be noted, that numerous research has been conducted in order to define the procedures that can help to solve the problems that translators encounter while translating audio-visual texts. Lörscher describes the procedures which lead to the best solution of a translation problem as translation strategies (Lörscher, 1991; Fernandez Guerra, 2012, p. 5). A set of translation strategies are suggested to create a metalanguage which is supposed to help solving various translation problems, according to Owji, performing literal translation is not an option in most cases. (Fernandez Guerra, 2012; Owji, 2013). Moreover, Kearns (2009, p. 283) indicates mental phenomena which are important along with the translation strategies. Georgakopoulou (2009) also notices that only a thorough analysis of a particular text may result in the right choice of the translation strategy. Several factors become important, e.g. function (relevance to the plot), connotation (information implied by the particular text), target audience's knowledge of the language, feedback effect and media related constraints. Schäffner (2004) argues that metaphor has been widely discussed within the discipline of translation studies, predominantly with respect to translatability and transfer methods. Transferring the meaning from the source language to the target one, from one culture to another, linguistic and cultural differences may occur (Schäffner 2004: 1256). Van den Broeck (1981) suggests that to achieve an ideal metaphor translation, three general translation methods can be distinguished: translation 'sensu stricto', which is employed to transfer source and target domains from SL to TL; substitution, which is a method of translation when the target domain of the SL is replaced with another target domain in the TL (however, the source domain in a way remains similar); paraphrase, which occurs when the metaphor of the SL is replaced with a non-metaphorical expression in the TL after the translation is performed (van der Broeck, 1981, p. 77).

Furthermore, Burmakova and Marugina (2014) distinguish several principles related to metaphor translation: metaphor is a cognitive process; conceptualization of mind and 
thoughts can be performed in linguistically similar or different ways; metaphor translation is the inter-cultural process. Thus, in order to perform a translation, the knowledge of intercultural ties is required.

However, some scholars suggest that translation of conceptual metaphors imply similar principles of translation to the traditional ones, such as substitution, paraphrase or deletion (Burmakova \& Marugina, 2014). Moreover, there are several approaches related to the conceptual metaphor translation. One of them is Mandelblit's (1995) taxonomy of cognitive translation, described by Al-Hasnawi (2007). He claims that the two schemes of both, the target language, and the source language, are involved in the cognitive mapping. Moreover, he suggests that metaphor translation is a challenging process as it employs complex cognitive procedures and is time consuming due to the search of different conceptual mapping. These rather cognitive factors cause difficulties and uncertainty of conceptual metaphor translation which may lead to the two outcomes of this kind of translation process - either the translator finds a similar cognitive domain in a TL, or he/she chooses another cognitive domain semantically somewhat fitting the one in the TL. The first choice results in an equivalent metaphor for the TL or, sometimes, simile, while the second choice results in a paraphrase, a footnote, an explanation or an omission (Al-Hasnawi, 2007).

On the other hand, Toury (1995) suggests that two additional procedures can be defined: (a) when a non-metaphorical expression in SL is replaced with a metaphor, (b) when a metaphor is added into the target text without any linguistic background. According to Pedersen and Lindquist (2002) combines the strategies defined by van den Broeck (1981) and Toury (1995) and for metaphor translation suggests: word-for-word translation; substitution (where one figure of speech in the ST is replaced by another in the TT); paraphrase (where the metaphor is replaced by a non-metaphorical expression); compensation (where a non-metaphorical expression is replaced by a metaphor); complete omission; compensation with a metaphor added in the ST (Pedersen, 2015, p. 167). However, Pedersen (ibid.) suggests that adding more metaphor translation strategies: specification (metaphor is preserved and explanations are added) and retention (metaphor is used in original language). The scholar notices, that metaphor translation in AVT can bring challenges due to the medium of audiovisual translation as other four channels of discourse become involved, such as, besides the verbal channel, the written language and the two non-verbal channels: audio and visual; still, all four of them being closely interrelated (Pedersen, 2015, p. 162). As several translation strategies are proposed for the translation of metaphors, cognitive linguists highlight the importance of the translator as well as cognitive factors involved in the translation of conceptual metaphors.

For a brief overview of scientific publications of the linguistic issues in the discourse of sport, it should be noted that the metaphorization of sport can be twofold: sport can be a source domain, or a target domain of conceptual metaphor. SPORT metaphors are quite frequently used in political communication for visualization and better understanding of political phenomena and related areas. The researchers in this field aim to reveal the metaphorization in the rhetoric of politicians and journalists. On the other hand, the SPORT discourse itself becomes a rich platform for the investigation of concepts involved in the process of metaphorization. As Katunar and Raffaelli (2016) state, the analysis of SPORT discourse in Croatian suggests that certain metaphorical expressions found in SPORT discourse are analyzed as "expressions of two conceptual metaphors: sport is war and sport is force". However, Shekhovskaya (2020) aims to "establish metaphorical models of MetaSelf in the English-language SPORT discourse". The author bases her 
analysis on a syntactic and semantic levels within the frame semantics and the semanticcognitive method as tools of an integrative approach. The metaphorical models of MetaSelf allows the researcher to identify several semantic groups of SPORT metaphors: the physiological metaphor, social metaphor, and morbial metaphor. As the researcher notices, each of the MetaSelf metaphor groups consists of the relevant semantic frames and slots, while the prevalence of the physiological metaphor may be observed. Furthermore, the author concludes that "the MetaSelf metaphor serves as an important linguistic means of pragmatically influencing the SPORT discourse, in which sport is likened to a person as a living organism" (Shekhovskaya, 2020).

Rashid Alzawaydeh (2018) aims to find the similarities and/or differences between English and Arabic in respect of the identified metaphorical concepts. His findings reveal that "the most predominant conceptual metaphor used in the English and Arabic headlines was FOOTBALL IS WAR and that there is a great similarity between the two languages in respect of the use of conceptual metaphors" (2018, p. 116).

The Polish SPORT discourse has been investigated by Lewandowski $(2009 ; 2012)$ who aims to demonstrate how soccer can be structured in terms of other SPORT (2009) or even 'non-violence', domains (2012). Moreover, the author also shows what kind of image is generated by soccer language metaphors. The comparative analysis of English and Polish data allows to observe the similarities and differences of the two languages in terms of the source domains that are exploited for the construction of the metaphors.

In the following chapters the methodology and the results of the current research will be presented.

\section{Methodology}

Translation strategies is an important factor which affects and/or modifies the conceptualization of SPORT in the target text. For the research, the analysis of three American SPORT films: "Pele. The birth of a legend", 2016 (further referred to as F1), "Trouble with the curve", 2012 (referred to as F2), and "Moneyball", 2011 (referred to as F3) and their subtitles was performed. The aim of the research was to analyse and compare the translation strategies employed in the translation of conceptual metaphors in the subtitles of SPORT films from English to Lithuanian. The empirical material consisted of 130 units in English and 130 in Lithuanian. The sample was created from all the conceptual metaphors identified in the three films: 45 conceptual metaphors were identified in F1, 28 conceptual metaphors were found in F2, and 57 conceptual metaphors were collected from F3. The first step of the analysis aimed at the identification and construction of conceptual metaphors in the Source language (SL), i.e. English, and their equivalents in the Target language (TL), i.e. Lithuanian. In this case the five-step conceptual metaphor identification procedure (Pragglejaz Group, 2007) has been applied. The second step consisted of the analysis of the translation strategies used for the translation of SPORT metaphors in the subtitles. The classification of translation strategies proposed by Lindquist (2002) and modified by Pedersen (2015) is applied in the research. However, compensation and specification strategies are excluded due to the specifics of audio-visual discourse translation. Thus, five translation strategies used for the translation of conceptual metaphors from English, as SL, to Lithuanian, as TL, have been identified: 1) word for word translation, 2) substitution, 3) paraphrase, 4) complete omission, and 5) retention.

The original texts and their translations were searched for the identification of source domains, while the target domain constituting the element "SPORT." Then the source text and the target text were compiled, and each segment in the sentence was analysed in terms of conceptualisation, keeping in mind their linguistic values, thus, identifying and 
interpreting their similarities and differences. As one of the most frequent, word for word translation strategy reflected the cases where the source and the target domains in the source and the target languages coincided, while analysing other translation strategies, the examples were classified according to the source domain present in the source text. The shift of the conceptualization in the translated text were analysed.

\section{Analysis}

\subsection{Word for word translation strategy}

The research results demonstrate that the most common translation strategy (48\%) in conceptual metaphor translation from English to Lithuanian is word-for-word translation. The most frequent source domains includes the concepts of WAR, BUSINESS, OBJECT. This translation strategy allows the translator to use a similar source domain in the target language. The examples of the translation strategy are provided below.

\section{A) SPORT IS WAR}

This group consists of metaphors which employ lexical items related to war terms while referring to SPORT. War metaphors are identified when the words, denoting fight, defeat, survive, attack, win or battle are used in the film discourse. Through the use of war metaphors, the opposition between the two fighting sides is emphasized, for instance:

1) We are defeated. / Mus nugalejo. (F1)

2) The 17-year-old with a humdinger of a shot giving Brazil a leg-up in this second half!/17metis nuostabiu šūviu itin pagelbsti Brazilijai antrajame kélinyje. (F1)

The choice of word-for-word translation strategy allows to keep the concept of WAR to be present in both examples. In the example No.1, the mapping from the source domain WAR to the target domain SPORT is accomplished with the help of the verb En. defeat / Lt. nugalejo. The example No.2 shows that in both SL and TL conceptual metaphor domains are preserved. The metaphorical expression SPORT IS WAR is construed with the help of the nouns En. shot / Lt. šūvis, representing the source domain WAR. The target domain SPORT is depicted from a larger context. In both cases, the conceptual blending of kicking a ball and shooting from a gun is preserved, and the conceptual mapping of ball kick and $a$ shot is retained in both SL and TL, therefore, the conceptual metaphor SPORT IS A WAR is preserved in both languages.

The example bellow emphasizes the element of POWER as a subdomain of WAR, consider:

3) Mabry, on one pitch, has shot the A's in front. / Mabris vienu smūgiu išvedé "Atletics" $i$ prieki. (F3)

The source domain is represented by the verbs En. shot / Lt. vienu smūgiu, where some semantic deviations occur, nevertheless, both verbs may be associated with the concept of WAR, therefore it is considered that the conceptual mapping in both cases stays the same. This way the conceptual metaphor is retained. It can be noted that in case of wordfor-word translation the translated expression retains the metaphorical meaning and the components of conceptual metaphor.

B) SPORT IS BUSINESS

The example No.4 the relation between SPORT and business is noticed:

4) Okay. People who run ball clubs, they think in terms of buying players. / Komandy vadovai mąsto per žaideju pirkimo prizmę. (F3)

The target domain SPORT is represented by the nouns En. player / Lt. žaideju and the source domain BUSINESS - by the nouns En. product / Lt. pirkimo. Both concepts are present in SL and TL. 
The analysis shows that in all cases of word-for-word translation the conceptual metaphor (SPORT IS BUSINESS) is retained. This reflects similar conceptualization in English as SL as well as Lithuanian as the TL.

C) SPORT IS AN OBJECT

The following examples illustrate the usage of word-for-word translation where the target domain is CONCRETE OBJECT.

5) Damon has eight hits in 18 at bats, a double, a triple, a couple of stolen bases. / Deimonas jau pataike 8 kartus iš 18, 1 dvigubas, 1 trigubas ir 2 pavogtos bazès. (F3)

6) I'd rather deal with you. You can give me Eckerton and $\$ 225,000$ in cash, and the Giants can't. / Tačiau mieliau sutarčiau su tavimi, nes tu man gali duoti Ekertonq ir $225000 \$, o$ "Giants" negali. (F3)

The example No. 5 shows that the bases in baseball can be treated as objects, therefore, base takes the features mapped from an object. In this case, the target domain SPORT is represented by the words En. has 8 hits / Lt. pataike 8 kartus, the source domain OBJECT is represented by the words En. stolen base / Lt. pavogtos bazés. After the translation is performed, both source and the target domains of the SL are transferred to the TL. In this particular metaphorical expression, verbs stolen (ST) and pavogtos (TL), indicate that bases are treated as objects. Conceptual metaphor (SPORT IS AN OBJECT) found in the original dialogue is retained in the TL.

The example No. 6 illustrates the case when a player is treated as an object. In this case, the target domain SPORT is represented by the player named En. Eckerton / Lt. Ekertonas and the source domain is represented by the money amount to be paid (object). The verb En. to give / Lt. duoti retains the same qualities in the TL as in the SL. After the translation is performed, the conceptual metaphor SPORT IS AN OBJECT in the TL is retained, with the same domains.

The cases analyzed reveal that the strategy of a word-for-word translation preserves the concepts used in both languages with no loss of metaphorical meaning.

\subsection{Substitution}

The other translation strategy used to translate conceptual metaphor is substitution, which was applied to $5 \%$ of all the metaphors. The examples below are classified according to the source domain present in the SL and illustrate the cases of conceptual shift in TL.

\section{A) SPORT IS A WAR}

The example No. 7 represents the case of substitution, consider the example below:

7) We should have beaten those guys./ Turëjom juos sumalti.(F1)

The target domain SPORT is implied from a broader context in both, SL and TL. The source domain WAR is rather evident in the SL as the expression "should have beaten" is used. The concept of beating implies fight and power over other, however, in the TL the concept of total demolishing may be detected as the word Lt. sumalti (to grind) is used. In this particular case, SPORT IS A WAR in the SL is replaced with the other conceptual metaphor SPORT IS CONCRETE OBJECT in the TL. Therefore, the source domain in SL WAR (en.beating) is substituted by the source domain CONCRETE OBJECT (represented by the noun lt. malimas/ en. grinding) in the TL. Thus, in this case the conceptualization of source domain in both languages varies.

B) PROGRESS IN SPORT IS UP

Another example where the strategy of substitution is used, represents different conceptualization of the source domain in SL and TL as well. 
8) Edson Arantes do Nascimento nicknamed Dico moved up to the junior team after a few unbelievable matches at the youth level. / Jaunuolis Edsonas Arantes do Nacimento, pravarde Džiko, perkeltas i jaunimo komanda po kelių neįtikétinu maču jauniu lygoje. (F1)

The phrasal verb "moved up" lies at the basis of the conceptual metaphor SPORT PROGRESS IS UP used in the SL, where the SPORT is target domain and the source domain is orientation UP. In the TL, the source domain is represented by the verb Lt. perkeltas (perkelti/to move an object), which indicates the change of the place of an object, not necessarily in the upward direction, therefore, the conceptual metaphor PROGRESS IS UP in SL is substituted with the conceptual metaphor SPORT IS AN OBJECT. Consequently, there is no loss of metaphorical meaning in TL.

C) SPORT IS AN OBJECT

The examples below illustrate the cases of substitution observed in the construction of the conceptual metaphors with AN OBJECT serving as source domain in SL.

9) The Yankees have taken the lead. / Jankiai išsiveržia i priekį. (F3)

The example above, in the SL, the target domain SPORT is represented by the name of a team En.Yankees / Lt. Jankiai. The word combination En. have taken the lead indicates the concept of an OBJECT, however, in TL the mapping between SPORT and moving forward is observed. In this case the conceptual metaphor SPORT IS AN OBJECT in SL is substituted with a conceptual metaphor WINNING IN SPORT IS MOVING FORWARD in TL. Nevertheless, both concepts indicate the Yankees team winning.

D) SPORT IS BUSINESS

The example No 10 illustrates the strategy of substitution, when the conceptual metaphor SPORT IS BUSINESS in TL is substituted by the SPORT IS AN OBJECT in SL:

10) I tried to convince Shapiro to pick him up last June, but he said he waddled like a duck.

/ Bandžiau įtikinti Šapirq, kad nupirktu ji praeita birželi, bet jis atréžè, kad Kevinas vaikšto kaip antinas. (F3)

The mapping of the features from the concept of OBJECT (en. pick him up) to the concept of SPORT is present in the SL. In the TL the source domain BUSINESS (lt. nupirktunupirkti/ en. to buy) borrows the features from the commercial frame, where the concept of PRODUCT/GOODS is represented by the word Lt. nupirkti (en. to buy). However, the source domain of SL (OBJECT) is indicated by the expression picking smth. up which implies things that can be gathered. Although the conceptualization varies in SL and TL, both instances indicate that the speaker was trying to convince Shapiro to sign that player. In both examples it can be seen that in the case of substitution, the concept representing source domain is being substituted with another close concept, which may be regarded as a part of bigger frame of TRANSACTION/COMMERCIAL EVENT (goods are objects in the transaction).

\subsection{Paraphrase}

This translation strategy has been used for the translation of $40 \%$ of the examples of the metaphors. The analysis of the examples is presented below.

\section{A) SPORT IS WAR}

In the example No. 11, the source domain WAR is represented by the verb "shoots" in the source language. The translated version uses the verb "spiria" (lt. spirti - to kick) which implies the action of moving the ball with the leg. As a result, the translated 
expression becomes a non-metaphorical one and conceptual metaphor SPORT IS A WAR is not present in SL due to the strategy of paraphrase.

11) He shoots and it's goal!/ Jis spiria ir ivartis! (F1)

The target domain SPORT in both, SL and TL, is represented by the semantically related words En. goal / Lt. įvartis.

In the example below, the target domain SPORT can be depicted from a larger context (the pronoun en. he / It. jis refers to a person looking for players) and the source domain is represented by the word scouting, which is part of the concept WAR: the features of scouting are mapped to the process of looking for new people.

12) He is scouting for the Santos Football Club! / Jis ieško talentu Santos futbolo klubui! (F1)

In the TL metaphorization is lost due to the strategy of paraphrase: the word combination Lt. žmogus ieškantis naujų žaidejjų/ en. person looking for new players is used, where the verb Lt. ieškoti (to be looking for) denotes an activity of a person directly.

13) A-Rod lines a shot to centre. The outfielder can't make the play. A-Rodas atmuša i centra. Žaidejas nesugeba užbaigti žaidimo.(F2)

In the example 13, the source domain WAR is expressed by the noun shot in SL, whereas in TL, due to the paraphrase strategy, the verb atmuša (En. plays back) is used, activating the frame of game, instead of war. Consequesntly, the metaphorisation is lost in the TL.

\section{B) SPORT IS BUSINESS}

The example below presents a metaphorical expression, where the mapping between a concept of SPORT and a concept of BUSINESS is seen:

14) Your goal should be to buy wins. / Reikètu siekti pergalès.(F3)

The target domain SPORT is represented by the word En. goal in the SL and the word Lt. pergales in TL. The source domain BUSINESS is represented by the word combination to buy a win in SL. The verb to buy implies the frame of the commercial event, where goal becomes currency used to buy a position of being winners. In the translated text the word Lt. laimejimas (En. win) is used, nevertheless, the translated expression is not metaphorical, as the concept of commercial event is no longer available due to the use of paraphrase in TL. The conceptual metaphor SPORT IS BUSINESS is replaced by a nonmetaphorical expression in the TL.

\section{C) WINNING IS UP / LOSING IS DOWN}

The mapping between the concepts of SPORT and the direction down is observed in the example below:

15) The A's, from 5-nothing down, now lead 6 to 5. / „Atletics" pralaiminejję 5-0, dabar išsiveržia i priekị. (F3)

The target domain SPORT is expressed by the name of the team in both, SL and TL, the source domain - direction DOWN implies the concept of LOSING, therefore, the metaphor LOSING A GAME IS DOWN may be construed in the SL. In TL, the source domain is being represented by the verb Lt. išsiveržti (en. to erupt, blow up), which is a part of the concept of PRESSURE IN THE CONTAINER conceptual frame. Thus, the conceptual metaphor is replaced with another metaphorical expression, which represents two different ways of conceptualization in both languages.

D) SPORT IS AN OBJECT

The strategy of paraphrase is used in the examples 15 and 16, provided below:

16) Brazil has taken the lead. / Brazilija pirmauja. (F1)

17) No one wants to pick him up. / ...jis niekam nereikalingas. (F3) 
The target domain can be depicted from a larger context - the mentioning of Brazil indicated metonymy, where the country name stands for a SPORT team. The source domain is expressed by the word combination has taken a lead in SL, which relates source domain with an object. The relation between the two domains is indicated by the verb to take. However, after the translation of this metaphorical expression, the source domain of this conceptual metaphor is lost. Only a target domain (lead/pirmauti) is retained in the TL. It can be noted that the conceptual metaphor SPORT IS AN OBJECT is replaced with a non-metaphorical expression. Nevertheless, the meaning of the expression remains the same.

Example No.17 illustrates the case, when a baseball player is perceived in terms of an object. The target domain of this expression is metonymically represented by the word player and the source domain - by the words pick him up in SL, where pick something up indicates objectification of the player, therefore in SL some of the distinctive qualities of an object are transferred to the player. However, after the translation is performed, it can be observed that the metaphorical expression is transformed. It is simply replaced with an adjective nereikalingas (en. unwanted, useless). Thus, the metaphor SPORT IS AN OBJECT is replaced with a non-metaphorical expression.

The analysis of the examples reveals that in the case of paraphrase, the target domain is retained in both SL and TL, while the source domain is often transformed in the TL. Transformation, on the other hand, often causes the loss of the metaphor in the TL, whereas the meaning of the entire expression is being conveyed.

\section{Complete omission}

This translation strategy is represented by only $3 \%$ of all the cases analysed. The example of complete omission is presented in the example below:

18) Bo Gentry's the kind of five-tool player /Bo Gentry vienas iš geresniu žaidejų...(F2)

In this sentence the conceptual metaphor HUMAN/SPORT ABILITIES ARE TOOLS may be construed, where the target domain SPORT is represented by the word player in SL, and the source domain - TOOL, by the word combination five- tool. In this case, of conceptual mapping, human ability to be a good player is treated as tool. However, in the translation of this metaphorical expression the source domain is not retained in TL. In case of complete omission the transformation of source domain is observed, as well as, the loss of conceptual metaphor.

\subsection{Retention}

Finally, the last translation strategy used to translate conceptual metaphors is retention. This translation strategy occurred in $4 \%$ of the cases of metaphorical expression translation The examples below provide a clear look at this translation strategy.

19) A brilliant attack from the Nordic Titans! / Nuostabi Šiaurès Titany ataka! (F1)

20) Our scouts will find players. / Mūsu skautai suras nauju žaidejjų...(F3)

21) Pete, scouts, good scouts, are the heart of this game. (SPORT IS A WAR) Pitai, skautai, geri skautai, yra šito žaidimo širdis. (F2)

In the example No. 19, the relation between the concepts of SPORT and WAR can be noted. The target domain SPORT in both SL and TL have been represented by semantically similar words - Eng. attack/Lt. ataka. In case of retention, the conceptual metaphor SPORT IS A WAR is retained, and it is identical in both cases. Furthermore, the same conceptual mapping, where the concept of moving forward is related to the frame of war (attack) is observed. 
Example No.20 contains an example of conceptual metaphor SPORT IS A WAR. In this case, the target domain SPORT (Eng. people looking for new players) is transferred from the SL to the TL (Lt. žmonés ieškantys nauju žaideju). Therefore, the source domain (scout) is transferred to the TL without transformation. Moreover, similar conceptualization is retained. Similar source domain concept, WAR, is used in the example No.21 as well. The instances of retention demonstrate that the strategy of adaptation is being applied, which helps to preserve similar conceptualization and transfer metaphors from SL to TL.

\section{Discussion}

During the last decades, the conceptual metaphor theory, suggested by George Lakoff \& Mark Johnson (1980) has been exploited by many researchers in various areas of linguistic research. Also, it should be mentioned that it has been criticized not only for various reasons, but also from various perspectives. As Koveczes (2016) indicates, these could be: "(1) the issue of methodology; (2) the issue of the direction of analysis; (3) the issue of schematicity; (4) the issue of embodiment; and (5) the issue of the relationship between metaphor and culture". In the case of the conceptual metaphors of sports, the issue of embodiment becomes important. Koveczes suggests the idea of "differential experiential focus" (2005), proposing that "embodiment consists of several components", which can be extracted and emphasized differently by different cultures or individuals. If this approach is taken into consideration, then the exploration of the embodiment of various concepts may take different turn, for instance, the embodiment of sport, as the results of the analysis demonstrate, consists of various elements and is complex. Furthermore, as it is seen in the analysis, various elements take central position in the metaphorical conceptualization of sports. Therefore, it is evident that the concept does not have a homogenious and unchanging structure. However, if the embodiment is treated as a complex issue, when individuals with different experiences focus on different aspects, it can be explained more easily how representatives of different cultures conceptualize various concepts, including sport. Furthermore, the role of the translator may not be underestimated as it is key for the retention of the metaphor from one culture to another, from one conceptual system to another. Depending on the chosen translation strategy, metaphors may be fully transferred or lost. Translators should be aware of the significance of metaphors in communication, and therefore, they should have competence for metaphor construction in the TL.

The limitations of the research include the analysis of two languages, English and Lithuanian, which limits the scope of the research to the representation of two cultures only. Further research, if such, could take into consideration the investigation of other indo-european languages in regard to the conceptualization of sport.

\section{Conclusion}

The results of the analysis revealed the most frequently employed translation strategy for the translation of the conceptual metaphors from English to Lithuanian was word-forword translation strategy. In these cases, the conceptual metaphors were fully transferred from SL to the TL. Meanwhile, paraphrase caused the loss of metaphors in TL, as the source domain was not transferred. Least frequently used translation strategies are substitution, when conceptual metaphors were replaced with another conceptual metaphors, and the strategy of complete omission, when the metaphorical expression was escaped in the TL. In cases of retention, the metaphorical expression in the TL remained identical to the one of the SL. 
The research also showed that the dominant type of conceptual metaphors used in the US SPORT films is SPORT IS A WAR and SPORT IS A BUSINESS. In the case of the WAR frame, the players or the teams are conceptualized as enemies, trying to defeat each other, therefore, the target domain SPORT may be represented by the words player, team and the source domain WAR, by the verbs conquer, fight, etc. In the case of BUSINESS frame, the commercial event scenario becomes evident, where players become goods which can be sold or bought. This frame involves objectification of humans and is related to another source domain - PEOPLE ARE OBJECTS.

\section{References}

Alzawaydeh, R. \& Alghazo, S. (2018). Analysing media discourse: The case of conceptual metaphors in football news headlines in English and Arabic. International Journal of Linguistics, 10(6), 116-133.

Al-Hasnawi, A. R. (2007). A cognitive approach to translating metaphors. Translation Journal, 11(3).

Beard, A. (1998). The Language of Sport. London and New York.

Bergh, G. (2011). Football is war: A case study of minute-by-minute football commentary. Veredas on line - Temátika, 2, 83-93.

Burmakova, E. \& Muragina, N. (2014). Cognitive approach to metaphor translation in literary discource. Procedia - Social and Behavioural Sciences, 154, 527-533. Available on: http://www.sciencedirect.com/science/article/pii/S1877042814056304

Charteris-Black, J. (2004). Corpus Approaches to Critical Metaphor Analysis. New York.

Fernandez Guerra A. (2012). Translating culture: problems, strategies and practical realities. A Journal of Literature, Culture and Literary Translation, 1(3), 1-27. doi: 10.15291/sic/1.3.lt.1.

Katunar D. \& Raffaelli, I. (2016). A discourse approach to conceptual metaphors: a corpusbased analysis of SPORT discourse in Croatian. Studia Linguistica Universitatis Iagellonicae Cracoviensis. Available on: https://www.ceeol.com/search/articledetail?id=476132

Georgakopoulou, P. (2009). Subtitling for the DVD industry. In: Cintas, J. D. \& Anderman, G. (Eds.), Audiovisual Translation: Language Transfer on Screen (pp. 21-35). Palgrave Macmillan.

Kearns, J. (2009). Strategies. In Baker, M. \& Saldanha, G. (Eds.), Routledge Encyclopedia of Translation Studies (pp. 282-285). London: Routledge.

Kövecses, Z. (2002). Metaphor. A Practical Introduction. Oxford UP.

Kövecses, Z. (2005). Metaphor in Culture: Universality and Variation. Cambridge UP.

Kövecses , Z. (2016). Conceptual metaphor theory. Some criticisms and alternative proposals. Available on: https://www.researchgate.net/publication/233562248_Conceptual_metaphor_theor y_Some_criticisms_and_alternative_proposals

Lakoff, G. \& Johnson, M. (1980). Metaphors We Live By. University of Chicago Press.

Кудрин С. (2011). Базовые метафоры спортивного дискурса как текстопорождающие модели. Научная библиотека диссертаций и авторефератов disser Cat, 2011. Available on: http://www.dissercat.com/content/bazovyemetafory-sportivnogodiskursakaktekstoporozhdayushchie-modeli\#ixzz2LigdP1D8>.

Lewandowski, M. (2009). Metaphors from Other SPORT in the Language of Soccer Evidence from English and Polish. In Nowak, P. \& Nowakowski, P. (Eds.), Język, Komunikacja, Informacja 4 (pp. 29-48). Poznań: Sorus. 
Lewandowski, M. (2011). The Rhetoric of Violence in English and Polish Soccer Reporting. In Nowak, P. \& Nowakowski, P. (Eds.), Język, Komunikacja, Informacja 4 (pp. 87-99). Poznań: Sorus.

Lewandowski, M. (2012). Football is not only war. Non-violence conceptual metaphors in English and Polish soccer language. In Taborek, J., Tworek, A., \& Zieliński, L. (Eds.), Sprache und Fußball im Blickpunkt linguistischer Forschung (pp. 79-95). Hamburg: Verlag Dr. Kovač.

Lörscher, W. (1991). Translation Performance, Translation Process, and Translation Strategies: A Psycholinguistic Investigation. Tübingen: Gunter Narr.

Matulina, Ž. \& Ćoralić, Z. (2008). Idioms in Football Reporting. In Lavric, E., Pisek, G., Skinner, A., Stadtler, W. (Eds.), The Linguistics of football (pp. 101-111). Tübingen.

Mandelblit, N. (1995). The cognitive view of metaphor and its implications for translation theory. Translation and Meaning, part 3, $483-495$.

Nordin, H. (2008). The Use of Conceptual Metaphors by Swedish and German Football Commentators. In Lavric, E., Pisek, G., Skinner, A., Stadtler, W. (Eds.), The Linguistics of football (pp. 113-120). Tübingen.

Owji, Z. (2013). Translation Strategies: A Review and Comparison of Theories. Available on: http://translationjournal.net/journal/63theory.htm

Pedersen, J. (2015). On the subtitling of visualized metaphors. The Journal of Specialized Translation, (23), 162-180.

Pragglejaz Group (2007). MIP: A method for identifying metaphorically used words in discourse. Metaphor and Symbol, 22(1), 1-39.

Semino, E. (2008). Metaphor in Discourse. Cambridge UP.

Schäffner, C. (2004). Metaphor and translation: some implications of a cognitive $\begin{array}{llll}\text { approach. Journal of } & \text { 36(7), }\end{array}$ doi:10.1016/j.pragma.2003.10.012

Shekhovskaya, J. (2020). Metaphors in English-language SPORT discourse: Linguistic means of "MetaSelf" expression. SKASE Journal of Theoretical Linguistics, 17(1), 87-101.

Toury, G. (1995) Descriptive Translation Studies and Beyond. Amsterdam \& Philadelphia: John Benjamins.

van den Broeck, R. (1981). The limits of translatability exemplified by metaphor translation. Poetics Today, 2, 73-87.

Vierkant, S. (2008). Metaphor and Live Radio Football Commentary. In Lavric, E., Pisek, G., Skinner, A., Stadtler, W. (Eds.), The Linguistics of football (pp. 121-132). Tübingen.

\section{Contact}

Prof. Saule Petroniene \& Prof. Saulute Juzeleniene

Kaunas University of Technology

K. Donelaičio str. 73

LT-44249 Kaunas

Lithuania

saule.petroniene@ktu.lt, saulute.juzeleniene@ktu.lt 